\title{
Inclusion in French Immersion in Canada: One Parent's Perspective
}

\author{
Callie Mady \\ Nipissing University \\ Katy Arnett \\ St. Mary's College of Maryland
}

\begin{abstract}
Through an examination of one mother's journals about her son's academic struggles to navigate the French immersion (FI) program in Canada, this article explores the tensions that exist when the construct of "inclusion" is juxtaposed against that particular second language-learning context. The analysis of the mother's journals revealed three distinct stress points between the two systems: the conflict between the diagnostic policies/procedures for learning disabilities and the ideals of inclusion, the "status" often accorded to FI and how that has naturally inhibited inclusion, and the limitations of the research on struggling students in FI. This article argues that in this age of celebrated learner diversity and calls for corresponding differentiated instruction, these stress points must be addressed in order for FI to foster a learning environment that is accessible and beneficial to all.
\end{abstract}

For many years, French immersion (FI) research has focused on identifying how and why some students struggle in FI and whether such struggles should "exclude" a student from the program (e.g., Genesee, 2007; Majhanovich, 1993; Mannavaryan, 2002). From our experiences as inclusive second language educators-turned-teacher educators and researchers, it is our belief that this near-exclusive focus on students and their (lack of) potential has limited research, practical, and political understandings of inclusion within the context of FI and potentially other second language classrooms.

Taking a cue from Brooks' (2002, pp. 73-74) use of his "messy" "story" about teaching Spanish to Grade 5 students to examine his theories about teaching and learning, this article uses one mother's journals about her child's tenure in the FI program to examine how existing theory, research, and policy about inclusion in FI intersected with classroom practice. Through the journal analysis, we discovered three underlying tensions shaping the educational experience of students with learning disabilities in FI: how the processes and policies shaping the identification/diagnosis of learning disabilities contradict the ideals of the inclusion movement, how the 
"status" often accorded to the FI program has deterred inclusive efforts, and what the research on struggling students in FI does and does not reveal about the connection between student needs and classroom practice. Given the current educational emphasis on acknowledging diverse learning styles and differentiated instruction, we believe that recognition of and attention to these tensions will expand the opportunities of students with learning disabilities.

Though one mother's journals are not sufficient to develop deep understandings of a particular situation, our prior experiences as teachers and current work as teacher educators and researchers of classrooms with diverse learning needs (e.g., Arnett, 2003, 2007, 2008; Mady, 2007a, 2007b, 2008) have told us that the experience shared in this article is not unique or isolated, and thus, worthy of discussion. We also felt that because the mother herself was an experienced second language teacher and teacher educator when this unfolded, it underscored how even intimate knowledge of "the system" was not enough to satisfactorily navigate the experience. In fact, the ensuing frustration led the mother to share her son's story-first orally and then by the provision of her journals - with the second author at a professional conference. Because the mother was familiar with the second author's work, she hoped the second author might be able to provide an additional perspective on the situation. With the permission of the mother, the second author sought the support of the first author - an experienced inclusive second language teacher-turned-teacher-educator-and-researcher-to analyse the journals. Through repeated readings, we came to believe that larger factors limited the son's progression in FI. Thus, when the second author shared that with the mother, the mother and son offered their permission to use these journals as the foundation of an article to bring Bob's Story ${ }^{1}$ to a larger audience.

\section{The Early Stages of Bob's Story: Excerpts from His Mother's Journals}

Bob's mother was somewhat uncomfortable sharing that she withdrew her youngest son from FI 2 years ago to ensure that his learning needs were met. She felt that she was a hypocrite since, in her own life as a teacher and teacher educator, she has advocated for French Second Language (FSL) education for all. Chronicling Bob's story through a journal allowed her to reflect on the situation with some detachment to try to understand this situation.

Bob's story took place in suburban Ontario in the school board where his mother taught for many years; while many features of Bob's story are linked to this context, many other features are likely applicable to other contexts. Her older son, Jesse, was in Grade 3 FI and doing well in the program when Bob enrolled in Grade 1 FI. Prior to his entry in Early French Immersion (EFI), there had been no indications that Bob would have particular learning needs. However, as the first excerpt from her journal revealed, Bob's struggles emerged quickly, as did the reactions to them.

The dual reactions to Bob's initial struggles in EFI are typical. On the one hand, the mother's reaction that her son was exhibiting atypical behaviours and attitudes when faced with schoolwork is often common to parents' accounts of the time preceding the diagnosis of a learning disability (Kenny \& McGilloway, 2007; Lavoie, 2008). The teacher's response reflected the reality of working with such young learners - developmental lags are common and not necessarily a sign of a problem. Since everything is new to students at this stage of their academic

\footnotetext{
${ }^{1}$ The mother's name does not appear in this article and a pseudonym chosen by her son was used for her son solely as means to protect the confidentiality of the schools and teachers involved.
} 
Figure 1

Excerpt A from Bob's Mother's Journal: The Origin of Bob's Struggles ${ }^{2}$

During Bob's Grade 1 year, which was in French $90 \%$ of the time, I began to recognise his difficulty with reading and spelling. Bob's frustration was most obvious when reading aloud and while preparing for dictations when he would often complain and procrastinate. Although we broached the subject with his teacher, she did not observe anything out of the ordinary and suggested that boys are often slower at developing literacy skills... The oral emphasis of the $\mathrm{Fl}$ program in Grade 1 and the different rates of language acquisition and literacy readiness in addition to Bob's coping mechanisms may have contributed to his challenges going unnoticed at school.

careers, it is possible that initial problems will work themselves out over time as the student becomes accustomed to school and its demands (Woolfolk, 2006).

Bob continued in EFI for Grade 2, but his problems became more apparent. He continued to struggle with homework, so those sessions typically ended in tears. The next excerpt from the journal outlines how the problems continued to manifest. Here, the gap between the mother's (and her partner's) perceptions and the teacher's perceptions of Bob's challenges began to widen. The frustration she felt at the time starts to become palpable in this excerpt, which is common to many parents' experiences with efforts to find support for their struggling children (Redmond \& Richardson, 2003). Further, the origins of the professional/parental dilemma become evident, as do the ways in which she drew on her knowledge of teaching second languages to diverse students to try to alleviate Bob's challenges. This latter practice - of offering insight into Bob's abilities and learning needs to the classroom teacher-is a highly encouraged strategy for enhancing the inclusive classroom experience (Duhaney \& Salend, 2000).

The past decade has seen a marked philosophical turn towards the early identification of learning disabilities (Lerner, 2008). This shift was propelled in part by two complementary factors: (a) data revealing that most learning disabilities were not being identified until after a student turned 12 and was thus far behind in school and (b) research demonstrating the earlier a student is provided with support that is congruent with his or her learning needs, the greater the progress the child will make in school (Mastropieri \& Scruggs, 2005; A. Turnbull, Turnbull, \& Wehmeyer, 2007). However, transitioning this philosophical shift to practiced reality has been difficult, as evidenced in Bob's story. Based on what has been shared, Bob's struggles were emerging by Grade 1, and his mother was actively seeking support to limit their impact. However, there were several factors that prevented early intervention.

Here we consider how the "warning signs" teachers are encouraged to use to screen for struggling students eliminated Bob from initial consideration for early intervention. By the mother's accounts, Bob's struggles went unnoticed because of his calm demeanour in school. Problematic behaviour is often cited as a sign that a child is struggling in the classroom; because the student is unable to complete classroom tasks, he or she is likely to become highly frustrated and have outbursts to avoid doing the work (Lerner, 2008; A. Turnbull et al., 2007). The absence of such behaviour in Bob, however, meant that he was viewed as an "average" student. Continuing to emphasize "problematic behaviour" as a strong indicator of a struggling student propels a stereotype about students with learning disabilities that makes helping such students all the more difficult. Granted, there are often other warning signs advertised to teachers (e.g., failure to complete an assignment, consistently submitting work late, irregular and inconsistent spellings), but student behaviour is often heralded as the biggest indicator of a problem (Duhaney \& Salend, 2000; Lerner, 2008).

\footnotetext{
${ }^{2}$ The journal entries have been edited to eliminate sections that do not apply to this analysis because of space constraints.
} 
Figure 2

Excerpt B from Bob's Mother's Journal: Bob's Year in Grade 2

Upon receipt of Bob's first term report card, we noted a discrepancy in his demonstrated difficulty at home and his satisfactory B average at school. Such a gap prompted us to request a parent-teacher interview; however, the teacher did not share our concerns. My partner and I requested that Bob be prompted to provide lengthier writing pieces rather than the short, quick mediocre work he was handing in, the teacher, however, accepted what he produced as opposed to demanding more of him. We proposed that he would perform better if provided with teacher conferencing and pre-writing tasks yet the teacher remained satisfied with Bob's production and to our knowledge did not implement the suggested strategies.

In a second interview, we asked for words for spelling to be used in context to help Bob contextualize them. We also asked for him to be given more time to complete reading assignments, to have some oral evaluations, but the suggestions were dismissed. Although these experiences of non-accommodation were contrary to my professional belief that teachers must differentiate instruction and evaluation to provide opportunities for all students to excel, they provided my partner and I with time to come to a consensus on the severity of the problem and the necessity for us to take further action.

I, then, approached the principal to ask for Bob to have a psychoeducational assessment by the school's psychologist. Given Bob's B average and the appropriateness of his behaviour at school, the principal laughed and dismissed my request. I remember standing in her office, incredulous, not having a response for the dilemma in which I found myself. At the end of Grade 2, we enrolled Bob in an academic support program outside of school.

In Excerpt C, we learn more about Bob's mother's efforts to have his needs identified and properly supported in the FI classroom, including further evidence of her efforts to secure inclass support. Most significantly, though, the process to identify Bob's challenges and the results of that endeavour are revealed.

Once Bob's mother and her partner had a sense of the precise nature of Bob's learning style and needs, they felt better positioned to get Bob the support he needed to find success in FI. Though they were plagued with many of the fears and worries other parents of children with learning disabilities share (Kenny \& McGilloway, 2007), they felt this identification would allow them to move ahead in this situation, but other barriers soon emerged. These barriers are united under three points that had their origins in these early stages of his story: procedures and policies regarding the identification of learning disabilities, the status of FI and how it inherently excludes students with special needs, and research on supporting students with special needs within FI.

\section{Procedures and Policies Regarding the Identification of Learning Disabilities}

As Bob's story took place in Ontario, those provincial laws governed the procedures and policies related to his diagnosis and to the development of his support program. In Kozey and Siegel's (2008) review, they stated that Ontario was the only province in the country that required a child to demonstrate a noticeable difference between his/her actual academic performance and psychometrically measured aptitude as a condition for diagnosis - henceforth known as the "intellectual-achievement discrepancy;" in Canada, there is still a lack of consensus about the best way to define and identify learning disabilities. As Lyon et al. (2001) argued, in order for a child to arrive at a point where such a discrepancy is noticed by stakeholders and acted upon accordingly, it may be too late for any interventions to make a difference in the child's school experience. This approach has been heavily criticized, in the Kozey and Siegel (2008) review and elsewhere (e.g., Lyon et al., 2001; Scruggs \& Mastropieri, 2002; Stanovich, 
Figure 3

Excerpt C from Bob's Mother's Journal: Evaluating Bob's Needs

Early in Grade 3, my partner and I requested an interview with his two teachers, English and French. In the absence of the English teacher, we began our meeting with the French teacher and described Bob's difficulties and our steps taken to date. Again, the teacher did not recognize Bob's challenges. We asked for accommodations to be made for Bob's spelling and to have him express his knowledge through a variety of means but our request was denied. The teacher claimed that accommodations as such were not made in the FI program. When the English teacher arrived she began the interview by telling us how well Bob was doing, when we inquired about his reading she also said he was progressing well. At that time, we told her that Bob could not read. A short time later, Bob received a D on his first term report card for English reading.

Although the discrepancy between our conversation and the report was disconcerting, Bob's report card provided evidence of his difficulties that I took back to the principal. She rapidly suggested that Bob switch to the English program. When confronted with my determination, the principal offered a compromise. She suggested that the teacher of special education could give Bob the Canadian Cognitive Abilities Test and if the results indicated problems, the principal would agree to have Bob put on the waiting list to receive a psychoeducational assessment. Agreed. Bob's CCAT test indicated that Bob was performing at the $5^{\text {th }}$ percentile for language and thus the principal agreed to put him on the list to be tested after having suggested a transfer to the English program. The waiting list for psychoeducational assessment at the time was a year and a half long, so we chose to have Bob tested privately. A choice we were fortunate to be able to make.

We continued to advocate for his inclusion in $\mathrm{FI}$ and asked for Bob to receive support from the teacher of special education. The principal denied the support explaining that support was not provided to students in the immersion stream. She continued to explain that immersion was considered an enrichment program where such support was deemed unnecessary.

The psychoeducational testing revealed that Bob's learning profile was highlighted by well-developed languagebased communication and thinking skills and are compromised by problems with visual memory functions and relatively weak skills for auditory analysis. Bob has extremely weak word analysis and decoding skills. His oral reading is laboured and quite inaccurate. Despite these significant problems, Bob exhibits above average comprehension. His spelling and writing skills are immature and not well developed. Bob evidences a statistically significant discrepancy between his overall cognitive abilities and his performance. The assessment suggests that Bob has high average cognitive abilities and a severe learning disability that is often characterized as dyslexia.

How could Bob understand that which he could not read? How could he see things differently? Why might he have problems in math? Incomprehension became fear. Fear not knowing what options the future held for Bob. Fear at not being able to solve this problem. Fear that if this information were shared that Bob would be labelled and less would be expected of him. On the other hand, such an evaluation provided evidence to have Bob identified as exceptional and then receive the support he required to meet with success in the FI setting.

1991, 1999), because of the large body of research that has failed to show that IQ tests can reliably and accurately distinguish "normal" students from those who have learning disabilities.

Kozey and Siegel (2008) argued that continually relying on this beleaguered approach "is potentially at odds with the purposes of educational evaluation, which is for needs assessment and intervention planning purposes" (p. 169). Bob's story demonstrates this conflict-and the problem of the "wait-to-fail" approach precisely. Because the diagnostic criteria rely on the presence of a discrepancy between intellect and achievement, the results of psychometric assessments are oriented towards the child's struggles - as we see in Excerpt C. Even though recommendations are ultimately made about how to support the child in the classroom context, they are typically based on an understanding of the child's deficits, not his/her capabilities. Jordan, Kircaali-Iftar, and Diamond (1993) have identified such a perspective to be "pathognomonic," meaning that it views disability as a pathos that is not open to remediation and implicitly argues that strategies and supports will have minimal impact on a child's growth in the classroom. Granted, this is congruent with the Ontarian definition of learning disabilities, but it is highly incongruous with the philosophy of inclusion, which maintains that all students can find success in school with appropriate supports from the teacher. To us, it seems problematic to use a 
diagnostic approach to learning disability that implicitly refutes the potential impact of teacher support, but then promote a classroom environment that lauds teacher supports as the best way to help struggling students.

Further, within the field of research examining reading disabilities (similar to Bob's), this deficit approach was argued to be heavily flawed as the identified students rarely found success in the classroom and there was considerable variation in the kinds of problems the students had (Fuchs \& Fuchs, 2006; Gunderson \& Siegel, 2001; Scruggs \& Mastropieri, 2002). To perhaps further underscore why these identification policies/practices deserve greater scrutiny, a case study of the test performance of a Grade 4 student with learning disabilities in FI revealed that the student's scores were stronger-and more reflective of her abilities in the classroom — when psychometric tests were replaced by more qualitative measures of her written language skills (Morton, 1985).

Consequently, in other jurisdictions there have been efforts to replace this older diagnostic approach with an alternative mechanism for identifying students in need of special education support, Response to Intervention (RTI). While RTI still lacks conclusive validity of its success (Burns, Jacob, \& Wagner, 2008), its emphasis on early and sustained interventions for struggling students - and not on psychometric tests - has caused it to gain momentum because it follows the "problem-solving" approach (Fuchs \& Fuchs, 2006). Essentially, in using RTI, teachers are to systematically implement a series of research-based strategies to help a previously identified group of struggling students. The students' progress is charted, and over time, the interventions are re-evaluated to determine their role in the student's success (or lack thereof), with modifications to the strategies made accordingly (Fuchs \& Fuchs, 2006). If a child fails to make progress after the third set of interventions, he/she is likely in need of more specific special education supports and would then be referred for formal special education assessment (Chamberlain, 2008). RTI is being touted because of its systematic focus on strategies for supporting struggling students and because it is more focused on what the child can do, rather than his/her deficits.

While only one province in Canada (Manitoba) acknowledges RTI in its conception of learning disabilities and the identification procedures, it is conceptually known to teachers everywhere (Kozey \& Siegel, 2008) ${ }^{3}$. Textbooks which outline general teaching methods consistently emphasize the importance of teachers monitoring student attitudes and learning behaviours, and when needed, to try new strategies, techniques, or resources to address a problem the student is experiencing (e.g., Freiberg \& Driscoll, 2005; Orlich, Harder, Callahan, Trevisan, \& Brown, 2006; Shrum \& Glisan, 2005); the practice is often paralleled to the Vygotskian practice of scaffolding (Wood, Bruner, \& Ross, 1976). Further, this "calibration" process is touted in policy documents that explain what to do when teachers suspect that a student is having problems in class that may be the result of a special need (e.g., Gauthier, 1995; Ontario Ministry of Education, 2000) and in the texts focusing on the best practices for teaching students with learning disabilities (e.g., Chamberlain, 2008; Lerner, 2008). To be clear, though, RTI is not a diagnostic tool of itself, but rather a new layer in the process of precisely identifying students' learning needs and how to best address them in the classroom.

\footnotetext{
${ }^{3}$ To be clear, RTI is not simply implementing intervention strategies and assessing their effectiveness. There are specific procedures and processes to help identify which students should be included in RTI sessions (typically, these students are having problems in the class), to indicate how the RTI sessions unfold and are evaluated, and these procedures are more complex than what has been described here. The discussion of RTI in this paper has been framed more to reveal the underlying concept of ongoing cycle of strategy implementation and assessment that is similar to regular teaching practices, as that is most germane to this analysis.
} 
When Bob was encountering problems with his FI homework, his mother implemented a cycle of strategies to see what did and did not help him with his work. Drawing on her language teaching background, she asked Bob to orally explain what he did and did not understand about readings - since he was struggling with the written component - or to write out more in his responses to questions than what was being asked (these strategies are referenced in Excerpts B \& C). The former strategy was somewhat successful, but its use meant that Bob was avoiding the kind of language that was most challenging for him. The use of the latter strategy, which did not circumvent Bob's challenges with language, allowed her to determine how well Bob understood the concepts conveyed in the text. Since the required one-word responses were more about assessing his ability to find the key word, which he usually did not find, his mother could not assess what he actually understood about the text. Certainly, such a scanning skill must be developed in early readers, but questions that require one-word responses do not give the teacher enough information to determine how or why a child came to that particular answer or if appropriate, made an error; this additional information in an answer is needed so that the teacher can better calibrate later instruction and help the child learn the targeted material (Chamberlain, 2008). When Bob wrote more, she saw what he did and did not understand about the text and knew what she needed to review. Further, as it pertains to language study, the more children produce in the target language, the more they recognize the limits of their understanding of the language (Swain, 1993). Sustained production therefore serves a second purpose of helping the student focus on needed areas of language development.

Thus, the mother's use of this "extended response" strategy addressed both Bob's needs and the goals of effective second language instruction-without circumventing the language form most problematic for him. She noticed its effectiveness and suggested it to his teachers, and while the suggestion was ignored in her view, her application of her own version of RTI to Bob's struggles show how the principles underlying the approach can be a useful tool. If learning disabilities continue to be identified through intellectual-achievement discrepancies (or otherwise linked to the discrepancy), the potential for teachers to realize and apply strategies that help the students learn within their ability and skill levels may be hampered.

\section{The Status of Fl as a Natural Barrier to Students with Special Needs}

The FI program has been at odds with students with special needs almost since its inception. Within the first few years of its creation, a series of studies (e.g., Bruck, 1978a, 1978b; Genesee, 1976; Trites \& Price, 1976, 1977) emerged questioning whether students who struggled to learn French should transfer to the English-only program and receive French instruction through the more traditional core French classroom context. A consequence of this debate was the development of the perception that FI was targeted to the academic elite, which was something we felt was evident in Bob's story. While Genesee (1992) had cautioned the research and teaching community early in the last decade that excluding students from immersion programs could lead to charges of elitism, it appears that this perception has resurfaced with the larger Canadian conscience last year, in part because of the efforts to eliminate the EFI program in New Brunswick (Gardner, 2008; Willms, 2008).

\footnotetext{
${ }^{4}$ That decision was made in March 2008. Following an outcry on the part of the community and researchers, there has been a modified decision: a new 'early' immersion program beginning at Grade 3 will be implemented to replace the former Grade 1 start.
} 
Several issues that surfaced during the highpoint of the debate about EFI in New Brunswick became gateways to larger discussions about the status of the FI program in general and the needs of students with special education needs. In New Brunswick, Willms (2008) pointed to "segregation according to ability" and "segregation based on behaviour" (p. 93). Analyses of the assessments of the emerging skills of young students points to the fact that most of the children enrolled in the EFI program had significantly higher scores on those literacy measures than students who would enrol in the core French language program; further, children with observable behaviour problems were less likely to enrol in EFI than the other program options. It could be argued that while such efforts would appear to be congruent with the aforementioned desire to identify learning disabilities as soon as possible in struggling students, the opposite appears to have happened. Attention has been devoted to those students who likely make the biggest academic gains within FI and strengthen its status as the best way to learn French in Canada. Students whose test scores indicated a potential for struggle might be directed elsewhere, though Gardner's (2008) critical op-ed piece in the Ottawa Citizen argued more strongly that "kids who struggle [in FI] are culled."

Special education legislation in Ontario and elsewhere is designed to ensure, at minimum, a child's access to the general education curriculum (Hutchinson, 2002). However, based on what happened in Bob's story, we argue that general education curriculum is typically interpreted to mean the "basic course of study" required of students in each and every grade level. FI, while the most effective program for developing proficiency in the target language (Genesee, 2007), is not viewed as a basic course of study; that distinction falls to core French because of its designation as the program satisfying the basic curricular goals in the provinces (Hutchinson, 2002; LeBlanc, 1990). As Excerpt C showed, the administrators in Bob's story viewed FI as an enrichment program - something that went above and beyond what was demanded-so exclusion from that program was not and is not likely viewed a violation of the legal mandates regarding special education. While we may see the validity in such logic, it is hard to reconcile that line of thinking with the current climate emphasizing "differentiated instruction" (Tomlinson, 1999) to meet learner needs. Moreover, it is not just to exclude students having difficulties from the method, EFI, shown to produce the best results (Genesee, 2007).

Rogers (2007) offered a potential rationale for this conflict between the law and practice, as she contended that "inclusive education policy, as a concept, process, and an experienced reality denies difficulty rather than embraces it" (p. 56, italics in original). While her argument is based on the realities of the United Kingdom, this denial stems from the need for teachers to demonstrate that students are learning in their classes. Similarly, there has always been a considerable amount of pressure on FI programs to demonstrate their success in making Anglophone children highly fluent in French (Lazaruk, 2007). It would seem, then, that populating the program with students most likely to find success in the program (as identified by the screening measures discussed earlier) and/or culling those students who struggle in the program would increase the likelihood of the program's success. In fact, M. Turnbull, Hart, and Lapkin (2003) cited the attrition of struggling students from FI programs as a possible explanation for the increased performance of Grade 6 FI students on measures that compared them to their Englishonly program peers. If this logic has been indeed informing practice, the time may have arrived for it to be seriously questioned.

Of course, attrition is to be expected from the program-after all, there are students who drop out of school in the mainstream program. Yet, if students eventually transfer to Englishonly programs because the FI program becomes academically difficult (Hayden, 1988; Obadia \& 
Theriault, 1995) does that not give further credence to the argument that FI is for the academic elite? There is no doubt that second language study is academically challenging - as is math study or science study. However, when students experience academic challenges in math or other content areas, they are not removed from those subjects. Supports are extended to the student with the goal of helping the student succeed in the classroom. As such support was not afforded to Bob, his mother withdrew him from the program in Grade 4.

\section{Research on Students with Learning Disabilities in FI}

As mentioned earlier, there has been a nearly 4-decade tradition of researching how and why children struggle in FI; whether those struggles can be definitively linked to language-based learning disabilities; and as shown in the previous section, whether these students should remain in the FI program (e.g., Majhanovich, 1993; Mannavaryan, 2002). Genesee's (2007) extensive review of the research on this topic does provide a lot of guidance to this debate; it focused on six major questions ${ }^{5}$, and while the first three could certainly connect to this account, the latter three questions are most pertinent to the next consideration of Bob's story.

As we already know, the question of whether to transfer Bob to the English-only program upon the discovery of his learning disabilities was eventually answered. To learn about how this process unfolded, we turn to the last excerpt from Bob's mother's journal, which describes what happened once she and her partner had received the results of the private assessments. The process began in Bob's Grade 3 year and was not resolved until he was in Grade 4.

Genesee (2007) reported how additional support — while commonly recommended for students in Bob's situation - is very rarely provided in FI. While the reasons for denying such support have not been explored officially in research, Bob's story and our professional experiences as classroom teachers suggest several possible reasons. First, this stems back to the issue we raised earlier about FI being a program reserved for the academic elite; the principal in Bob's story defined FI as an optional enrichment program, which by definition, would be something "above and beyond" what is expected. As for other reasons for denying the accommodations to Bob, we turn to the last two questions Genesee (2007) explored in his review-which pedagogical interventions are needed to support students who are currently having or at-risk for having problems in the program and what is the knowledge base teachers (in both immersion and special education programs) would need in order to provide meaningful support to the students.

There has been very little research on the kinds of support that can make immersion more inclusive (e.g., Bournot-Trites, 2004; Morton, 1985; Rousseau, 1999). The absence of such a research corpus and limited research corpus on effective teaching practices within FI (e.g., Akcan, 2004; Bouffard \& Sarkar, 2008) - after over 40 years of FI—could imply to teachers that there is no need to be inclusive. It may also be indicative of an absence in their teacher education programming. Such implications could explain some of the reactions when Bob's mother suggested

\footnotetext{
${ }^{5}$ The six questions posed in the Genesee (2007, pp. 656-657) review include: (1) Out of concern for their basic education, should at-risk students or students with identified disabilities be discouraged from enrolling in French immersion? (2) Do reliable and valid measures exist that would enable stakeholders to identify - near the point of school entry — which students would most likely succeed in French immersion ? (3) Would at-risk students benefit more from certain immersion programs (e.g., early, mid, late) than others? (4) If a student's challenges are identified/diagnosed after enrolling in the program, should he/she transfer out of the program? If so, at what point? (5) If at-risk students or students with identified challenges remain in the program, what supports are needed to help them achieve academic success, and which language should be used to offer such supports? (6) What skills and knowledge base should immersion teachers have in order to effectively address the needs of at-risk students and students with identified needs?
} 


\section{Figure 4}

\section{Excerpt D from Bob's Mother's Journal: The Decision to Transfer Bob Out of FI}

After meeting with a colleague to discuss the results of Bob's test, we decided to have Bob presented at the next $\mathrm{IPRC}^{6}$. Bob was declared to have a communication learning disability at the following IPRC meeting and was recommended for in-school support. Such support, however, would only be made available if Bob transferred to the English program. Determined to forge a path for Bob in the FI program, I asked, in writing, for the accommodations to be made in all subjects except Math. The school, however, would not permit accommodations to the French program.

In Grade 4, I shared the psychoeducational assessment and some of the suggested strategies with the French teacher: chunking of reading and writing tasks, extra time for in class assignments, no penalty for spelling and yet no accommodations were made. I was disheartened, frustrated, and tired-the strategies were not being used. Dismayed, I then called our home school, where Bob attended kindergarten, and arranged a meeting with the principal. In the meeting that followed, I described our situation to date and explained that I was investigating all of my options. The principal was quick to inform me that Bob's kindergarten teacher did not recommend FI for Bob. I took responsibility for my decision to enrol him and proceeded to ask what kind of support Bob would receive and what class he would be in if we transferred him. The principal explained that he would be put in a split grade rather than in the available single grade class despite his difficulties. Next, I called the Roman Catholic Separate School Board to see if they had immersion classes where Bob could receive the necessary support-no. I also contacted a private school to investigate their abilities to meet his needs-no again. I came to the conclusion that the public school board was his best option. Yet, a meeting with Bob's FI principal limited my choices. Given that Bob was not living in the FI school's catchment area the principal informed me that Bob could finish the year but then he would have to return to his home school. My belief that my son could be successful in FI had hit the final wall.

strategies to Bob's teachers. Teachers are now strongly encouraged to use research-based practices to teach students with special needs (Chamberlain, 2008). Since there is scant research on the topic, the EFI teachers may feel they lack sufficient knowledge to be inclusive educators because of this conflict between the mandates and the research reality.

Genesee (2007) argued, however, that the findings from research on supporting students with such learning challenges in the English-first language programs (e.g., August \& Shanahan, 2006; Genesee \& Geva as cited in Genesee, 2007) do support the potential for those interventions to be successful in FI programs. While it is not directly discussed in the Genesee review, it is worth mentioning that the traits that make learners successful in immersion (e.g., strong decoding skills, phonological awareness) have cross-linguistic transfer, demonstrating Cummins' (1984, 1996) Common Underlying Proficiency (CUP) theory. Cummins (1984) argued that to effectively support students in the early stages of bilingual education who were having languagebased challenges, teachers must provide support in the child's first language (L1); because of the nature of CUP, as the skills in the L1 become stronger, the skills in the target language will become stronger too. Bournot-Trites (2004) has provided evidence that CUP also works in the reverse direction, as supports in the second language enhance the skills in the L1. This could have substantial potential for FI stakeholders concerned about providing support in French to struggling students.

Like Genesee (2007), we certainly believe that more research on this relationship between the interventions and the language in which they are implemented is sorely needed. We also know from our experiences as teacher educators that more pre-service and in-service education must be offered to FI and other second language teachers about how to best meet the needs of the included students.

\footnotetext{
${ }^{6}$ The Identification and Placement Review Committee (IPRC) holds the responsibility of formally "designating" a student to have special education needs in Ontario and outlining the recommended supports for the student (Ontario Ministry of Education, 2000).
} 


\section{Conclusion}

Though an analysis of a unique experience with inclusion in the FI context, this account has illuminated several tensions that could explain why and how the two constructs have not been able to successfully coexist to this point. In using one parent's journal to highlight events that characterized her son's struggle to manage his learning needs and find success in FI, we have outlined how the barriers raised by the identification practices of learning disabilities, the perception of FI as a program for the academic elite, and the lack of research on effectively supporting struggling students in FI made it extremely challenging for inclusion to be a part of Bob's FI experience - from both political and practical standpoints. From our vantage points, we believe the time has come for all stakeholders in this process to take active steps to ensure that what happened to Bob (and undoubtedly to other students like him) does not happen again. In fact, we believe that the survival of FI depends on its ability to show how it can be inclusive of a wide range of learner needs; a language program cannot continue to thrive if it does not challenge itself to do better.

\section{References}

Akcan, S. (2004). Teaching methodology in a first-grade French immersion class. Bilingual Research Journal, 28(2), 267-277.

Arnett, K. (2003). Teacher adaptations in core French: A case study of one grade 9 class. The Canadian Modern Language Review, 60(2), 173-198.

Arnett, K. (2007). Accommodating the exceptional learner in French immersion: Strategies for addressing issues of teacher beliefs and classroom practice. Journal d'Immersion, 29(2), $23-26$.

Arnett, K. (2008). Exploring the use of student perspectives to inform topics in teacher education: Issues in creating an inclusive core French classroom. Canadian Journal of Applied Linguistics, 11(1), 63-81.

August, D., \& Shanahan, T. (2006). Developing literacy in second-language learners: A report of the National Literacy Panel on Language-minority Children and Youth (pp. 175-184). Mahwah, NJ: Lawrence Erlbaum.

Bouffard, L. A., \& Sarkar, M. (2008). Training 8-year old French immersion students in metalinguistic analysis: An innovation in form-focused pedagogy. Language Awareness, 17(1), 3-24.

Bournot-Trites, M. (2004). Peer tutoring: A parent-school initiative to improve reading in French immersion primary grades. In The State of FSL Education in Canada 2004 (pp. 56-57). Ottawa, ON: Canadian Parents for French.

Brooks, F. B. (2002). "My theory is intact; however..." Reflections on teaching Spanish to fifth graders. Foreign Language Annals, 35(1), 73-84.

Bruck, M. (1978a). The suitability of early French immersion for the language disabled child. Canadian Journal of Education, 3, 51-72.

Bruck, M. (1978b). Switching out of French immersion. Interchange, 9(4), 86-94.

Burns, M. K., Jacob, S., \& Wagner, A. R. (2008). Ethical and legal issues associated with using Response-to-Intervention to assess learning disabilities [Electronic version]. Journal of School Psychology, 46(3), 263-279.

Chamberlain, S. (2008). Effective practices for students with disabilities in inclusive classrooms. In Y. S. Freeman, D. E. Freeman, \& R. Ramírez (Eds.), Diverse learners in the mainstream classroom: Strategies for supporting ALL students across content areas (pp. 77-100). Portsmouth, NH: Heinemann.

Cummins, J. (1984). Bilingualism and special education: Issues in assessment and pedagogy. Avon, United Kingdom: Multilingual Matters. 
Cummins, J. (1996). Negotiating identities: Education for empowerment in a diverse society. Los Angeles, CA: California Association for Bilingual Education.

Duhaney, L. M. G., \& Salend, S. J. (2000). Parental perceptions of inclusive educational placements. Remedial and Special Education, 21(2), 121-128.

Freiberg, H. J., \& Driscoll, A. (2005). Universal teaching strategies (4th ed.). Boston: Allyn Bacon.

Fuchs, D., \& Fuchs, L. S. (2006). Introduction to Response to Intervention: What, why, and how valid is it? Reading Research Quarterly, 41(1), 93-99.

Gardner, D. (2008, July 23). The real reason we send our kids to French immersion. The Ottawa Citizen. Retrieved August 1, 2009, from http://www.dangardner.ca/Coljul2308.html

Gauthier, B. (1995). Intervention levels for students with learning problems in French immersion. Vancouver, BC: Vancouver School Board.

Genesee, F. (1976). The role of intelligence in second language learning. Language Learning, 26, 267280.

Genesee, F. (1992). Second/foreign language immersion and at-risk English-speaking children. Foreign Language Annals, 25(3), 199-213.

Genesee, F. (2007). French immersion and at-risk students: A review of research evidence [Electronic version]. The Canadian Modern Language Review, 63(5), 655-687.

Gunderson, L., \& Siegel, L. S. (2001). The evils of the use of the IQ test to define learning disabilities in first- and second-language learners. The Reading Teacher, 55(1), 48-55.

Hayden, H. M. R. (1988). French immersion drop-outs: Perspectives of parents, students, and teachers. Reading-Canada-Lecture, 6(4), 222-235.

Hutchinson, N. L. (2002). Inclusion of exceptional learners in Canadian schools: A practical handbook for teachers. Toronto, ON: Prentice Hall.

Jordan, A., Kircaali-Iftar, G., \& Diamond, C. T. P. (1993). Who has the problem, the student or the teacher? Differences in teachers' beliefs about their work with at-risk and integrated exceptional students. International Journal of Disability, Development, and Education, 40(1), 45-62.

Kenny, K., \& McGilloway, S. (2007). Caring for children with learning disabilities: An exploratory study of parental strain and coping. British Journal of Learning Disabilities, 35(4), 221-228.

Kozey, M., \& Siegel, L. S. (2008). Definitions of learning disabilities in Canadian provinces and territories [Electronic version]. Canadian Psychology, 49(2), 162-171.

Lavoie, T. (2008). How to know if your child has ADHD or learning differences: The importance of an accurate diagnosis. Exceptional Parent, 38(5), 68-69.

Lazaruk, W. (2007). Linguistic, academic, and cognitive benefits of French immersion [Electronic version]. The Canadian Modern Language Review, 63(5), 605-627.

LeBlanc, R. (1990). National core French study: A synthesis. Ottawa, ON: The Canadian Association of Second Language Teachers.

Lerner, J. (2008). Learning disabilities (11th ed.). New York: Houghton Mifflin.

Lyon, G. R., Fletcher, J. M., Shaywitz, S. E., Shaywitz, B. A., Torgeson, J. K., Wood, F. B., et al. (2001). Rethinking learning disabilities. In C. E. Finn, Jr., A. J. Rotherham, \& C. R. Hokanson, Jr. (Eds.), Rethinking special education for a new century (pp. 259-287).Washington, DC: Thomas B. Fordham Foundation.

Mady, C. (2007a). The suitability of core French for recently arrived adolescent immigrants to Canada. Canadian Journal of Applied Linguistics, 10(2), 177-196.

Mady, C. (2007b). Allophone students in second-official language programs. The Canadian Modern Language Review, 63(5), 727-760.

Mady, C. (2008). Opening the doors to official language learning for allophones. Ottawa, ON: Canadian Parents for French.

Majhanovich, S. (1993). The mainstream environment in Canada: Is there a place in French immersion for learning disabled students? The Canadian Modern Language Review, 9, 67-72.

Mannavaryan, J. M. (2002). The French immersion debate: French for all or all for French? Calgary, $\mathrm{AB}$ : Detselig Enterprises. 
Mastropieri, M. A., \& Scruggs, T. E. (2006). The inclusive classroom: Strategies for effective instruction (3rd ed.). Upper Saddle River, NJ: Pearson.

Morton, L. L. (1985). Qualitative versus quantitative test performance for a learning disabled French immersion student: A case study. Canadian Journal for Exceptional Children, 2(2), 43-47.

Obadia, A. A., \& Theriault, C. M. L. (1995). Attrition in French immersion programs: Possible solutions. ERIC Document Reproduction Services ED400674.

Ontario Ministry of Education. (2000). Individual education plans: Standards for development, program planning, and implementation. Toronto, ON: Queen's Printer for Ontario.

Orlich, D. C., Harder, R., Callahan, R., Trevisan, M. S., \& Brown, A. H. (2006). Teaching strategies: A guide to effective instruction (8th ed). New York: Houghton Mifflin.

Redmond, B., \& Richardson, V. (2003). Just getting on with it: The service needs of mothers who care for young children with severe/profound and life-threatening intellectual disability. Journal of Applied Research on Intellectual Disabilities, 16, 205-218.

Rogers, C. (2007). Experiencing an "inclusive" education: Parents and their children with "special educational needs.' British Journal of Sociology of Education, 28(1), 55-68.

Rousseau, N. (1999). A French immersion learning disabilities program: Perspectives from students, their parents, and their teachers. Mosaic, 6, 16-26.

Scruggs, T. E., \& Mastropieri, M. A. (2002). On babies and bathwater: Addressing the problems of identification of learning disabilities [Electronic version]. Learning Disability Quarterly, 25, 155168.

Shrum, J. L., \& Glisan, E. W. (2005). Teacher's handbook: Contextualized language instruction (3rd ed.). Boston: Thomson/Heinle.

Stanovich, K. (1991). Discrepancy definitions of reading disability: Has intelligence led us astray? Reading Research Quarterly, 26, 7-29.

Stanovich, K. (1999). The sociopsychometrics of learning disabilities. Journal of Learning Disabilities, 32(4), 350-361.

Swain, M. (1993). The output hypothesis: Just speaking and writing aren't enough. The Canadian Modern Language Review, 50, 158-164.

Tomlinson, C. A. (1999). Mapping a route toward differentiated instruction. Educational Leadership, 57(1), 12-16.

Trites, R. L., \& Price, M. A. (1976). Learning disabilities found in association with French immersion programming. Ottawa, ON: University of Ottawa Press.

Trites, R. L., \& Price, M. A. (1977). Learning disabilities found in association with French immersion programming: A cross-validation. Ottawa, ON: University of Ottawa Press.

Turnbull, A., Turnbull, R., \& Wehmeyer, M. L. (2007). Exceptional lives: Special education in today's schools. Upper Saddle River, NJ: Pearson.

Turnbull, M., Hart, D., \& Lapkin, S. (2003). Grade 6 French immersion students' performance on largescale reading, writing and mathematics tests: Building explanations. Alberta Journal of Educational Research, 49(1), 6-23.

Willms, J. D. (2008, July/August). The case for universal French instruction [Electronic version]. Policy Options, 29(7), 91-96.

Wood, D., Bruner, J. S., \& Ross, G. (1976). The role of tutoring in problem-solving. Journal of Child Psychology and Psychiatry, 17, 89-100.

Woolfolk, A. (2006). Educational psychology (10th ed.). Boston: Allyn \& Bacon.

\section{Authors' Note}

Correspondence concerning this article should be addressed to Katy Arnett, Department of Educational Studies, St. Mary's College of Maryland, 18952 E. Fisher Road, St. Mary’s City, MD 20686. Email: kearnett@smcm.edu 